\title{
A semi-automated non-radioactive system for measuring recovery of RNA synthesis and unscheduled DNA synthesis using ethynyluracil derivatives
}

\author{
Yuka Nakazawa $^{\mathrm{a}}$, Shunichi Yamashita ${ }^{\mathrm{a}+}$, Alan R Lehmann ${ }^{\mathrm{b}+}$ and Tomoo Ogi ${ }^{\mathrm{a}, *}$ \\ ${ }^{\text {a }}$ Department of Molecular Medicine, Atomic Bomb Disease Institute, Graduate School of \\ Biomedical Sciences, Nagasaki University, 1-12-4, Sakamoto, Nagasaki 852-8523, Japan \\ ${ }^{b}$ Genome Damage and Stability Centre, University of Sussex, Falmer, Brighton BN1 9RQ, \\ United Kingdom \\ *corresponding author: togi@nagasaki-u.ac.jp / Tel: +81-95-819-7103 / Fax: +81-95-819-7104 \\ ${ }^{+}$These authors contributed equally to this work.
}

\begin{abstract}
Nucleotide excision repair (NER) removes the major UV photolesions from cellular DNA. In humans, compromised NER activity is the cause of several photosensitive diseases, one of which is the skin-cancer predisposition disorder, xeroderma pigmentosum (XP). Two assays commonly used in measurement of NER activity are 'Unscheduled DNA synthesis (UDS)', and 'Recovery of RNA synthesis (RRS)', the latter being a specific measure of the transcription-coupled repair sub-pathway of NER. Both assays are key techniques for research in NER as well as in diagnoses of NER-related disorders. Until very recently, reliable methods for these assays involved measurements of incorporation of radio-labeled nucleosides. We have established non-radioactive procedures for determining UDS and RRS levels by incorporation of recently-developed alkyne-conjugated nucleoside analogues, 5-ethynyl-2'-deoxyuridine $(\mathrm{EdU})$ and 5-ethynyuridine (EU). EdU and EU are respectively used as alternatives for ${ }^{3} \mathrm{H}$ thymidine in UDS and for ${ }^{3} \mathrm{H}$-uridine in RRS. Based on these alkyne-nucleosides and an integrated image analyser, we have developed a semi-automated assay system for NERactivity. We demonstrate the utility of this system for NER-activity assessments of lymphoblastoid samples as well as primary fibroblasts. Potential use of the system for largescale siRNA screening for novel NER defects as well as for routine XP diagnosis are also considered.
\end{abstract}

\section{Keywords}

Nucleotide excision repair (NER); Transcription coupled repair (TCR); Recovery of RNA synthesis (RRS); Unscheduled DNA synthesis (UDS); Xeroderma pigmentosum (XP); Cockayne syndrome (CS).

\author{
Abbreviations \\ 5-ethynyl-2'-deoxyuridine (EdU); 5-ethynyuridine (EU).
}

\section{Introduction}


Genetic information stored in DNA is continuously threatened by various types of DNA damaging activity. A failure of DNA repair in living cells induces genomic instability, and may eventually result in cancer and other pathological consequences [1].

Xeroderma pigmentosum (XP) and Cockayne syndrome (CS) are autosomal recessive photosensitive genodermatoses. XP patients show sunlight-induced pigmentation changes and skin-cancer predisposition, and in some cases neurological degeneration and mental retardation. CS patients are not susceptible to skin carcinogenesis, but, in addition to sun sensitivity, they show dwarfism, severe mental retardation, microcephaly, developmental disorders, and premature aging [2-4]. Most XP and all CS cases are associated with a deficiency in nucleotide excision repair (NER), which deals with major UV-photolesions as well as many chemical DNA adducts [5, 6]. There are two sub-pathways of NER. Global genome repair (GGR) is a relatively slow process that removes damage throughout the genome[7]. Transcription-coupled repair (TCR) is a more rapid process that removes damage specifically from the transcribed strand of genes that are being actively transcribed[8].

XP results from defects in one of eight genes, XPA through $G$ and variant, whereas two genes, $C S A$ and $C S B$, are responsible for CS. The XP A-G proteins are involved in different steps of NER. Recognition of the damage in GGR is mediated by the XPE and XPC proteins. The next step is opening out of the damaged region of DNA by TFIIH, which contains the XPD and XPB proteins and utilizes the helicase activity of XPD and the ATPase activity of XPB. After verification of the damage by XPA, the DNA is cleaved on the 5' side of the damage by XPF and its partner protein ERCC1, and on the 3' side by XPG. The damaged section is then removed and replaced by DNA polymerases, ligases and their accessory proteins.

TCR differs from GGR in the initial damage recognition stage. In TCR, stalling of the RNA polymerase at the lesion is the initiating signal, and results in recruitment of the CSB and CSA proteins. The role of these proteins is to recruit the later NER proteins and various chromatin remodeling proteins to allow the subsequent steps of NER to take place. The roles of TFIIH, XPA, F and G are the same in TCR and GGR. Thus CS is associated with specific defects in TCR, whereas XP patients are defective in GGR alone (XPC and E) or in both GGR and TCR.

Trichothiodystrophy (TTD) is a third disorder associated, in about $50 \%$ of cases, with defects in NER. In these cases, most are defective in $X P D$, a few in $X P B$ and a few in a third gene TTDA. The products of these three genes are all components of TFIIH, which has independent roles in NER and in transcription. It is thought that mutations affecting the NER function result in XP, whereas those affecting transcription as well result in TTD. A few patients in the XPB, $\mathrm{D}$ and $\mathrm{G}$ groups have the combined features of XP and CS.

Diagnosis of NER-related-disorders as well as NER research typically involves determining the level of nucleotide incorporation associated with DNA repair activity $[9,10]$. GGR contributes $90-95 \%$ of NER and can be assessed by damage-induced, non-S-phase, DNA repair synthesis activity, termed unscheduled DNA synthesis (UDS) [9]. Patients with XP (except for the variant form, which is deficient in the translesion synthesis DNA polymerase, poln [11]), XP combined with CS (XP/CS), and NER-deficient TTD, are GGR-defective and can be diagnosed by determining UDS levels. TCR can be readily measured by 'recovery of RNA synthesis (RRS)' levels after DNA damaging treatment. UV irradiation results in a decrease in RNA synthesis rates, which recover rapidly in normal cells, largely as a consequence of TCR [10]. In CS cells, which lack TCR, RNA synthesis does not recover and remains at a low level. 
In XP-diagnostic laboratories, $254 \mathrm{~nm}$ UVC-irradiation is commonly used for inducing DNA damage; radio-labeled nucleosides, ${ }^{3} \mathrm{H}$-thymidine and ${ }^{3} \mathrm{H}$-uridine, have been generally used to measure UDS and RRS respectively $[9,10]$. In both these assays, nuclear silver grain counting following autoradiography has been established as an accurate and sensitive but timeconsuming and laborious technique, while direct liquid scintillation counting of acid-insoluble DNA or RNA is a quicker but less quantitative method [12].

We have recently described a non-radioactive method for UDS measurement that entails incorporation of an alkyne-conjugated thymidine analogue, 5-ethynyl-2'-deoxyuridine (EdU) [13], in combination with a direct fluorescent azide coupling reaction using commercially available reagents (Invitrogen) [14]. This method provides a rapid and accurate alternative to the autoradiography-based assay; however, the method has so far been limited to determining GGR-activity and XP diagnosis as, until very recently, only a deoxy- form of the alkyne-nucleosides was available. Although this procedure obviates the need for laborintensive autoradiographic procedures, our published procedure still uses manual analyses of individual coverslips, which is a potential disadvantage for routine diagnoses or screeningbased operations.

Here we report the development of a semi-automated assay system for NER activity that is applicable to both UDS and RRS measurements using EdU and the more recently available 5-ethynyluridine (EU) [15] . The EU-based RRS assay complements our recently reported EdU-based UDS assay. We have employed improved protocols suitable for plastic 96well plates and GE's 'In-Cell-Analyzer' - an automated plate scanner equipped with a fluorescent microscope and a CCD camera. We demonstrate that the technique is compatible with lymphoblastoid samples and is also applicable to large-scale siRNA screening projects.

\section{Materials and methods}

\subsection{Cell strains and cultures}

Normal 1BR [16] and 48BR [16], XP-patient-derived XP12BR (XP-D) [13], XP15BR (XP-A) [17], XP13BR (XP-C) [13], XP21BR (XP-C, this study) and XP20BE (XP-G) [18], and CS-patient-derived CS16PV (CS-A, Miria Stefanini, personal communication), CS20PV (CS-B, Miria Stefanini, personal communication) and CS10LO (CS-B) [19] cells were human primary fibroblasts. Normal 277 and 701 (both purchased from RIKEN), and XP-patientderived XPL5 (XP-V) [20] and XPL15OS (XP-A) [20] are EBV-immortalised Blymphoblastoids (LCLs). Fibroblasts and LCLs were cultured in respectively Dulbecco's Modified Eagle Medium (DMEM) and RPMI1640, both supplemented with 10\% fetal calf serum (FCS) (Gibco-BRL) and penicillin-streptomycin (Wako).

\subsection{UDS assay with incorporation of ethynyldeoxyuridine (EdU) and automation using the In-} Cell-Analyzer

5-ethynyl-2'-deoxyuridine (EdU) is available from Invitrogen [14]. To optimise UVinduced UDS by EdU incorporation and its measurement in microtiter plates with the In-CellAnalyzer, effects of UV-dose, EdU concentration and incubation period, fluorodeoxyuridine (FdU), and fixation, permeabilisation and staining conditions were examined. 48BR cells were plated at confluent density in 96-well plastic microtiter plates (Falcon) and cultured for 16h in DMEM supplemented with 10\% FCS. Cells were washed with PBS, followed by irradiation with a range of doses $\left(5 \sim 40 \mathrm{~J} / \mathrm{m}^{2}\right)$ of UVC $\left(254 \mathrm{~nm}, 50 \mu \mathrm{W} / \mathrm{cm}^{2}\right)$. After UV-irradiation, cells were immediately incubated for different time periods $(0.5 \sim 4 \mathrm{~h})$ in serum-free DMEM supplemented with various concentrations of $\operatorname{EdU}(2.5 \sim 20 \mu \mathrm{M})$, and additionally supplemented with or without $1 \mu \mathrm{M}$ FdU (SIGMA). Serum-free medium was used as serum often contains 
thymidine, which competes with EdU for incorporation into DNA. Cells were then washed with PBS, followed by fixation and permeabilisation. We examined two different fixation protocols: for 1-step fixation, cells were fixed and permeabilised in PBS containing 2\% paraformaldehyde, $0.5 \%$ triton X-100, and $300 \mathrm{mM}$ sucrose for $20 \mathrm{~min}$ on ice; for 2-step fixation, cells were fixed for $10 \mathrm{~min}$ on ice with PBS containing $3.7 \%$ paraformaldehyde, followed by permeabilisation with $0.5 \%$ triton X-100 in PBS for $5 \mathrm{~min}$ on ice. After extensive washing with PBS, cells were blocked for 30 min with 10\% FCS in PBS at room temperature. To diminish background signal, we established the following improved azide-coupling staining protocol. Cells were incubated for $1 \mathrm{~h}$ with $25 \mu \mathrm{M}$ Alexa Fluor 488 azide (Invitrogen) in freshly-prepared 50mM Tris- $\mathrm{HCl}$ (TBS) ( $\mathrm{pH} 7.3$ ), supplemented with $4 \mathrm{mM} \mathrm{CuSO}_{4}$ and $10 \mathrm{mM}$ sodium ascorbate, followed by extensive washing with PBST $(0.05 \%$ Tween 20$)$. Cells were then incubated with $20 \mathrm{ng} / \mathrm{ml}$ DAPI in PBS for $20 \mathrm{~min}$, and twice washed with PBST, followed by fixation in PBS containing 3.7\% paraformaldehyde for $20 \mathrm{~min}$.

We found that $20 \mathrm{~J} / \mathrm{m}^{2} \mathrm{UVC}$-irradiation, followed by $5 \mu \mathrm{M}$ EdU incubation for $4 \mathrm{~h}$ without FdU supplement, and the 1-step fixation protocol was the optimal condition for the UDS assay on plastic 96-well plates. This condition was used for all experiments unless otherwise stated.

Image acquisition and data processing were automated using GE's In-Cell-Analyzer system: plates were scanned with a CCD-camera-equipped scanning microscope, and captured images were directly processed using the automated Developer software programmed for detection of nuclei (DAPI staining), measurements of the fluorescent intensity (Alexa Fluor 488 staining), and subtraction of background signals calculated from the fluorescent intensity of circumference of nuclei. All non-S-phase cells in a single captured field (60 70 cells) were evaluated, and the median fluorescence density values of discrete nuclei were calculated from the pixels contained in each nucleus. Data points presented in the figures are the averages calculated from ten different fields. Developer Toolbox scripts describing the assay protocols are available from the authors.

\subsection{Non-radioactive RRS assay by incorporation of ethynyluridine (EU) using the In-Cell- Analyzer}

5-ethynyluridine (EU) is available from Invitrogen [15]. To optimize RRS measurement by EU incorporation using plastic plates and the In-Cell-Analyzer, we again analysed the effects of various parameters. 48BR cells were plated at confluent density on 96well plastic microtiter plates and cultured for 16h in DMEM supplemented with $10 \%$ FCS. Cells were washed with PBS, followed by irradiation with a range of doses $\left(5 \sim 20 \mathrm{~J} / \mathrm{m}^{2}\right)$ of UVC. After UV-irradiation, cells were incubated for different time periods $(0 \sim 24 \mathrm{~h})$ for RNA synthesis recovery in DMEM supplemented with $1 \%$ FCS. Cells were then immediately incubated for different time periods $(0.5 \sim 4 \mathrm{~h})$ in serum-free DMEM supplemented with various concentrations of EU $(50 \sim 1000 \mu \mathrm{M})$. Cells were then washed with PBS, followed by fixation and permeabilisation by the two different protocols, and azide-coupling reaction and DAPI staining as described above.

We found that $5 \mathrm{~J} / \mathrm{m}^{2} \mathrm{UVC}$-irradiation, followed by $4 \mathrm{~h}$ incubation for RNA synthesis recovery and $2 \mathrm{~h}$ labeling in media supplemented with $100 \mu \mathrm{M} \mathrm{EU}$, and the 1-step fixation protocol was the optimal condition for the RRS assay on plastic 96-well plates. This condition was used for all experiments unless otherwise stated.

Image acquisition and data processing were automated using the In-Cell-Analyzer and the Developer software as described above. All cells in a single captured field were evaluated, and the median fluorescence density values of discrete nuclei were calculated from the pixels contained in each nucleus. Data points presented in the text are the averages calculated from ten different fields. 


\subsection{EdU-based UDS assay on lymphoblastoid samples}

EBV-immortalised lymphoblastoid cells (LCLs) were cultured in RPMI1640

supplemented with $1 \%$ FCS (low-serum media) for $72 \mathrm{~h}$ prior to the experiments. This step is needed to minimise the number of cells in S-phase as DNA replicative synthesis significantly interferes with UDS signals in LCL samples. We tried different UV-doses $\left(5 \sim 20 \mathrm{~J} / \mathrm{m}^{2}\right)$, EdU concentrations $(5 \sim 10 \mu \mathrm{M})$ and incubation time-periods $(1 \sim 4 \mathrm{~h})$, and fixation and permeabilisation protocols (data not shown), and found that the following condition is optimal for the UDS assay for LCL samples. Cells were centrifuged, suspended in PBS and UVC irradiated $\left(20 \mathrm{~J} / \mathrm{m}^{2}\right)$ in non-tissue-culture-treated plastic dishes, followed by $1 \mathrm{~h}$ incubation in serum-free RPMI1640 supplemented with $10 \mu \mathrm{M}$ EdU. After washing with PBS, cells were fixed and permeabilised in PBS containing $2 \%$ paraformaldehyde, $0.5 \%$ triton $\mathrm{X}-100$, and $300 \mathrm{mM}$ sucrose for $20 \mathrm{~min}$ on ice. Cells were then blocked for $30 \mathrm{~min}$ with $10 \%$ FCS in PBS at room temperature. Azide-coupling and DAPI staining were performed as described above, but all done in eppendorf tubes and 0.5mM EDTA was included in all steps after the azidecoupling reaction. Processed cells were finally suspended in PBS supplemented with $0.5 \mathrm{mM}$ EDTA, followed by cytospin-centrifugation at $1500 \mathrm{rpm}$ for $2 \mathrm{~min}$ using multi-chamber cytofunnels (Thermo). Image acquisition and data processing were automated using the InCell-Analyzer system as described above.

\subsection{RNA interference}

Pre-designed siRNA oligos targeting for XP- and non-NER-related repair genes, and scrambled non-targeting controls were the MISSION siRNA purchased from SIGMA (the siRNA oligo sequences can be obtained from the authors upon request). siRNA transfection was performed using Xtream gene (Roche) transfection reagent according to the manufacturer's instruction. 10nM of siRNA oligos were transfected in suspension, followed by one additional transfection cycle $24 \mathrm{~h}$ after the first transfection. UDS and RRS assays were performed $48 \mathrm{~h}$ after the first siRNA transfection. Knockdown efficiencies were confirmed by western blot.

\section{Results}

\subsection{Development of an automated EdU-based UDS assay system using the In-Cell- Analyzer}

We first optimised the EdU-based UDS assay conditions for the automated system (Figure 1A). 48BR normal human primary fibroblasts were seeded into 96-well plates. Cells were then UVC $(245 \mathrm{~nm})$ irradiated with a range of doses, followed by incubation for different time periods with serum-free media containing various concentrations of EdU, with or without the thymidylate synthetase inhibitor, fluorodeoxyuridine (FdU) (Figure 1B-1E). Incorporated EdU was detected by the Alexa Fluor 488-azide coupling reaction using a modified couplingbuffer after permeabilisation of the cells using two different protocols (details described in Materials and Methods). 96-well plates were then processed by the In-Cell-Analyzer. We were able to detect DNA damage-dependent EdU incorporation, which denotes UDS activity, in fibroblasts cultured on plastic-96 well-plates, as previously observed in coverslip-based experiments (Figure 1B). DAPI staining clearly enabled the detection of nuclei, which is needed for cell-cycle determination as well as for the automated nuclear fluorescent measurements (Figures 1A, 1B); though we noted that the background fluorescent intensity was relatively higher than in the coverslip-based assay (data not shown), an appropriate background subtraction process, which is also a feature of the software (details described in Materials and Methods, Figure 1A), clearly diminished interference of unwanted fluorescent signals inside the nuclei (data not shown). We found that the EdU concentration did not 
significantly affect the UDS-specific nuclear fluorescent intensity levels over the range examined (Figure 1C). A supplement of FdU contributed only slightly to the UDS specific EdU incorporation, whereas the permeabilisation processes significantly affected the fluorescent intensity (Figure 1D). As we previously demonstrated [13], UDS dependent EdU incorporation was increased in proportion to UV dose and incubation time period (Figure 1E). We found that 10-20 J/m $\mathrm{m}^{2} \mathrm{UVC}$ irradiation, $5 \mu \mathrm{M}$ EdU for $4 \mathrm{~h}$ labeling, and the one-step fix and permeabilisation process, are the optimum conditions for the EdU assay with the automated system.

\subsection{Rapid assessment of GGR-deficiency in XP cells by the semi-automated UDS assay}

We next assessed the UDS levels of several NER-deficient fibroblasts and normal controls. To evaluate the reproducibility and variation of the UDS levels assayed in plastic 96well-plates, each cell line was plated in quintuplicate and assayed as shown in Figure 2A. Satisfyingly, plate-to-plate variation (data not shown) as well as well-to-well variation were both very small (compare bars 1-5, and 8-12 in each panel), indicating that the assay is very reproducible. We noted that the UDS levels of normal fibroblasts from five different individuals assayed in this system varied between $96-102 \%$ of 48BR cells (Figure 2B, 2C, and data not shown); this variation was significantly smaller than that obtained with different assays based on cells plated on coverslips using either autoradiography or EdU incorporation [13]. We further determined the UDS levels of typical NER-deficient cell lines; as shown in Figure 2D-2G, severe NER-deficient XP cell lines, XP15BR (XP-A) and XP20BE (XP-G), showed no detectable UDS (Figure 2D,E), whereas intermediate NER-deficient XP12BR (XPD) and XP13BR (XP-C) cell lines elicited weak but statistically significant UDS activities (Figure 2F,G).

As CS cells are only compromised in the TCR pathway of NER, a UDS deficiency has not been detected by conventional procedures. Figure $2 \mathrm{H}$ and Supplemental Figure $\mathrm{S} 1$ indicate modest but statistically significant UDS reductions in CS-A and CS-B cells, indicating that the automated system may be able to detect minor UDS-deficiencies because of improved objectivity and reproducibility. It may however transpire that, with a broader range of normal and CS cell-lines, these variable UDS reductions in CS cell-lines may in fact fall within the normal range; nevertheless, the system is at least sensitive enough to detect cell line-to-cell line UDS variations, consistently.

The UDS levels that we have measured were in good agreement with the levels assayed by thymidine incorporation and with our EdU based measurements on coverslips (Supplemental Table S1) [13], indicating that the system provides a convenient, but sensitive and accurate assay for UDS.

\subsection{EU-based non-radioactive recovery of RNA synthesis (RRS) assay using In-Cell- Analyzer}

After our recent publication, we noticed that EU, which can be used for in vivo RNA labeling, had become commercially available (Invitrogen). We assumed that an EU based RRS assay might be a good alternative for the classical radioisotope based assays. As an EU based RNA labeling protocol has been recently published [15], we tested if EU incorporation could be used to detect the delay in RNA synthesis recovery typical of TCR-deficient CS fibroblasts, and whether it can be assessed on the automated system (scheme described in Figure 3A). In normal fibroblasts, we could detect EU incorporation-specific fluorescence signals over the EU concentration range we examined; this incorporation was significantly inhibited by UV irradiation (Figure 3B). Unlike in the case of EdU labeling, permeabilisation procedures did not influence the fluorescence levels (data not shown). We found that, with our improved coupling protocol described in detail in Materials and Methods, a $2 \mathrm{~h}$ labeling period with 
$100 \mu \mathrm{M}$ EU was sufficient for RNA synthesis detection in normal 48BR cells without DNA damaging treatment (Figure 3C, 3D), even though the original publication noted that a higher EU concentration and longer incubation period are optimum for the EU labeling [15]. (We also noted that the EU labeling efficiency did not increase linearly with incubation time (Figure 3D)). We then examined RNA synthesis recovery after UVC irradiation (Figure 3E). For CS diagnostic tests, a typical protocol measures RNA synthesis levels 16-24 h after irradiation of samples with different UV doses [21]. As shown in Figure 3E, using the automated EU assay, RNA synthesis recovers after a few hours in response to UV in normal fibroblasts, while in CS-B cells (CS10LO), no significant recovery was observed even $24 \mathrm{~h}$ after irradiation with $\mathrm{UV}$ doses of $10 \mathrm{~J} / \mathrm{m}^{2}$ and above. However, we decided to use $5 \mathrm{~J} / \mathrm{m}^{2} \mathrm{UVC}$ irradiation and $4 \mathrm{~h}$ recovery for the RRS assay in the system, as the shorter recovery period diminishes the time needed for the assay, and this condition provided good discrimination between normal and CS cells. Although increased discrimination could be obtained with longer recovery times, we chose to use this short recovery protocol, so that we can complete a set of UDS and RRS assays in a single day. CS cell-lines were assayed using this system and statistically significant reductions in RRS were clearly detected, while almost complete RNA synthesis recovery was observed in normal fibroblasts (Figure 4A-4D, and Supplemental Figure S2). We also detected reduced recovery in TCR-defective XP-A (XP15BR) and XP-D (XP12BR) cells (Figure 4E, $4 \mathrm{~F}$ ), while recovery in two XP-C cells, XP13BR (mild UDS-deficiency) and XP21BR (severe UDS-deficiency), which are compromised in GGR but not TCR, approached that in normal controls (Figure 4G, 4H). These results reflect those obtained with conventional assays (eg Mayne and Lehmann, 1982) and demonstrate that the EU-based RRS assay in conjunction with the In-Cell-Analyzer provides a convenient and accurate measurement of RNA synthesis recovery, and is suitable for rapid diagnoses of TCR-compromised disorders.

\subsection{Rapid UDS measurements for lymphoblastoid cells provided by the EdU-based assay}

We further tested whether the EdU-based UDS assay might also be applicable to peripheral lymphocyte samples: lymphocyte-based diagnoses would be less invasive than existing assays that require fibroblasts from skin-biopsies. B-cell enriched lymphocytes can be prepared from whole-blood samples by use of immuno-magnetic-beads as well as Ficoll-based separation reagents. As a first step towards analyses using lymphocytes, we performed EdUbased UDS assays on EBV-immortalised lymphoblastoid cell lines (LCLs) established from normal donors (277, and 701), and from XP-patients (XPL5, XP-V; XPL15OS, XP-A) using the experimental scheme shown in Figure 5A. LCLs were cultured for $72 \mathrm{~h}$ in low serum media to diminish the number of cells in S-phase. Cells were then UVC irradiated $\left(20 \mathrm{~J} / \mathrm{m}^{2}\right)$, followed by $1 \mathrm{~h}$ incubation in serum-free medium supplemented with $10 \mu \mathrm{M}$ EdU (experimental details described in Materials and Methods). UV-induced UDS was detected in normal 277 and 701 LCLs (Figure 5B, 5C), while no detectable UDS was observed in XP-A deficient XPL15OS (Figure 5D). As expected, we observed normal UDS levels in the XP variant XPL5 cells (Figure 5E). These results confirm that the EdU-based UDS assay might be applicable for XP diagnosis with clinical blood samples.

\subsection{A potential use of the automated system for large scale screens}

A major advantage of using automated systems is that they can be used for large-scale screens. We considered if our set-up might be applicable to searching for novel genes in NER using an siRNA-based screen. To test the system, we designed a small-scale pilot experiment knocking-down XP and genes unrelated to NER using a set of siRNA oligos. 48BR cells were transfected with siRNA in 96-well plates, and UDS and RRS levels were measured by the system (Figure 6A; details of RNA interference are described in Materials and Methods). As expected, we detected a reduction in UDS and RRS in the cells transfected with XP-targeting 
siRNAs, whereas it remained unchanged in cells transfected with either control siRNA or siRNAs against NER-unrelated genes (Figure 6B, 6C). Note that no attempt was made in this pilot study to optimize knock-down conditions. As siRNA-based gene targeting is often imperfect, screening systems have to be sensitive and reproducible enough to pick-up small changes in NER activity. Our system is sensitive enough to detect the effects of knockingdown known XP genes, suggesting that it can be used for an extensive screen.

\section{Discussion}

The most commonly used techniques for UDS and RRS measurements involve ${ }^{3} \mathrm{H}-$ thymidine labeled nucleoside incorporation, followed by evaluation of silver-grain counting after autoradiography of tissue-culture coverslips [9]. Since it is both accurate and sensitive, this laborious technique has remained in vogue even after several alternative methods have been reported [12, 21-23]. Bromodeoxyuridine (BrdU) and bromouridine (BU) are respectively popular alternatives for DNA-labeling by ${ }^{3} \mathrm{H}$-thymidine and RNA-labeling by ${ }^{3} \mathrm{H}$-uridine. Nevertheless publications using BrdU for UDS and BU for RRS assays have been very limited due to their restricted sensitivity and resolution $[22,24]$. Recently developed alkyneconjugated nucleoside analogues, EdU and EU, have been proved to be useful for S-phase DNA labeling and detection of nascent RNA synthesis, respectively [14, 15]; however it has not been clear whether labeling with these nucleoside analogues was sufficiently robust to enable their use in UDS and RRS. In our preceding report, we demonstrated that an EdU-based UDS assay is accurate enough to be an alternative to autoradiography [13]; the biggest improvements from employing EdU to the UDS assay are the obviation of the need to use radioactive materials, and of time-consuming and skilled procedures. We showed in our report, that the entire UDS assay can be completed within a day from preparation of the assay coverslips, and also that the method is compatible with standard cell-biology techniques such as immunofluorescent staining and labeling of cells with micro-latex beads, which are often used in combination with the UDS assay.

In this report, we firstly automated the UDS assay. This approach dramatically improved the sensitivity of the EdU-based method; the system achieved more than $\sim 50 \%$ reduction of the background signals (Compare ref. 13 and Figure 2), which is now as good as the conventional autoradiographic technique [9]. The assay is sensitive and reproducible enough to distinguish between normal controls and TCR-deficient CS cells, as well as between severely UDS-deficient XP-A or XP-G cells and moderately deficient XP-D or XP-C cells (Figure 2B, 2C and 2H, and 2D-2G). Secondly, we adopted an RNA precursor, EU, which has recently become commercially available, for the RRS assay. The EU-based RRS assay is also suitable for use in the automated system. Both UDS and RRS levels can be measured in 96well plates as sensitively as using autoradiography. We finally evaluated the system for several applications. We showed that the EdU-based UDS assay is applicable to lymphoblast samples. Although the results are not as precise as with fibroblasts, this blood-sample-based approach may eventually benefit the patients as it obviates invasive skin-biopsies.

We also investigated the suitability of the system for large-scale screening. We designed a pilot siRNA screening experiment; it demonstrated that a micro-titer plate-based NERactivity assay can be used for screening. The automated NER-assay system can process $\sim$ twenty 96-well plates per day (In-Cell-Analyzer 1000). This enables the evaluation of both UDS and RRS activities of $\sim 100$ different samples to be carried out in a day, if the screening is performed using the format shown in Figures 2A and 4A. The above EdU or EU -based assays can be transferred to a commonly used fluorescent microscope equipped with a motorised stage and focus, and a monochrome CCD camera. We have set up a system using a Zeiss 
microscope, Axio-Observer Z1, equipped with a long working distance lens, HRm monochrome CCD camera, and an ASI's motorised X-Y stage, MS-2000. Sequential image acquisition and analysis are performed automatically on a macro program running Axiovision software (the script is available from the authors).

The NER-deficiency assessments by incorporation measurements of EdU and EU have the potential to become standard techniques in basic NER research as well as in clinical diagnosis of NER related diseases. They also have the potential for use in chemotherapy, for example to measure NER in tumor cells to predict sensitivity to platinum-based therapy.

\section{Conflict of interest}

None.

\section{Acknowledgements}

We are grateful to Heather Fawcett for technical assistance. This work was supported by a Grant in aid for Honeybee Research from Yamada Apiculture Center Inc., Special Coordination Funds for Promoting Science and Technology from Japan Science and Technology Agency (JST), a Grant in aid for Seeds Innovation (Type-A) from JST, a Grant in aid for Scientific Research KAKENHI (20810021) from Japan Society for the Promotion of Science (JSPS) to T.O.; a Grant in aid for Scientific Research KAKENHI (21810022) from JSPS to Y.N.; a Global COE Program from the Ministry of Education, Culture, Sports, Sciences and Technology of Japan to T.O., Y.N. and S.Y.. CS-patient-derived CS16PV and CS20PV are kind gifts from Dr. Miria Stefanini (Pavia).

\section{FIGURE LEGENDS}

Figure 1. EdU-based semi-automated UDS assay using the In-Cell-Analyzer. (A) An experimental scheme for the UDS assay. Cells were plated on plastic 96-well plates, UVCirradiated $(254 \mathrm{~nm})$ with a range of doses $\left(0 \sim 40 \mathrm{~J} / \mathrm{m}^{2}\right)$, followed by incubation for different time periods $(0.5 \sim 4 \mathrm{~h})$ in serum-free media supplemented with various concentrations of EdU $(2.5 \sim 20 \mu \mathrm{M})$, and additionally supplemented with or without $1 \mu \mathrm{M}$ FdU. Fixation (1- or 2-step), conjugation of Alexa Fluor 488-azide to the incorporated EdU, and nuclear DAPI staining are described in Materials and Methods. Image acquisition and data processing were automated using GE's In-Cell-Analyzer system. (B) Typical UDS images captured by the In-CellAnalyzer. Normal 48BR cells were cultured in 96-well plates and UVC irradiated $\left(20 \mathrm{~J} / \mathrm{m}^{2}\right.$; $+\mathrm{UV}$ ) or mock-treated (-UV), followed by $4 \mathrm{~h}$ incubation with medium supplemented with 5 $\mu \mathrm{M}$ EdU. Cells were processed as described in (A). Circles and dashed circles indicate non-Sphase and S-phase cells, respectively. (C) Effects of EdU concentration: 48BR cells were UVC irradiated $\left(20 \mathrm{~J} / \mathrm{m}^{2}\right)$, followed by $4 \mathrm{~h}$ incubation in media supplemented with various concentrations of EdU $(2.5 \sim 20 \mu \mathrm{M})$. Cells were processed as described in (A). (D) Effects of FdU and fixation process on the UDS assay. 48BR cells were UVC-irradiated $\left(0 \sim 40 \mathrm{~J} / \mathrm{m}^{2}\right)$, followed by $4 \mathrm{~h}$ incubation in media supplemented with $10 \mu \mathrm{M}$ EdU, and with or without $1 \mu \mathrm{M}$ FdU. Cells were then fixed with two different protocols. (E) Effects of UV dose and EdU incubation time-period for the UDS assay. 48BR cells were UVC irradiated at the indicated doses, followed by incubation in media supplemented with $5 \mu \mathrm{M}$ EdU for different time periods $(0.5 \sim 4 h)$. Cells were processed as described in (A). Bars or data points, and error bars indicate average fluorescent intensity of discrete nuclei and standard errors, respectively. 
Figure 2. Reproducible detection of NER-activity by the UDS assay system. (A) The EdUbased UDS assay on normal and NER-deficient fibroblasts was performed together in a single 96-well plate. (B-H) The indicated human primary fibroblasts were seeded in a 96-well plate in quintuplicate as shown in (A). The assay plate was half-covered by a plastic-board wrapped in aluminum foil and UVC irradiated (closed bars, $20 \mathrm{~J} / \mathrm{m}^{2}$; open bars, no-UV), followed by $4 \mathrm{~h}$ incubation with media supplemented with $5 \mu \mathrm{M}$ EdU. Cells were then processed as described in Figure 1. Bars and error bars indicate average fluorescent intensity of discrete nuclei and standard errors, respectively. $\Delta$ represents UDS difference between irradiated and unirradiated samples. Percentages indicate UDS levels normalised against 48BR (red lines). Student's t-test was performed to evaluate differences in UDS levels between cell lines: 48BR vs. 1BR, not significant ( $\mathrm{p}=0.5$ ); XP15BR vs. XP20BE, not significant ( $\mathrm{p}=0.3)$; 48BR vs. CS10LO, CS10LO vs. XP12BR, XP15BR vs. XP13BR and XP12BR vs. XP13BR, significant $(\mathrm{p}<0.01)$.

Figure 3. EU-based semi-automated RRS assay using In-Cell-Analyzer. (A) An experimental scheme of the RRS assay. Cells were plated on plastic 96-well plates, UVC-irradiated with a range of doses $\left(0 \sim 20 \mathrm{~J} / \mathrm{m}^{2}\right)$, followed by incubation for different time periods $(0 \sim 24 \mathrm{~h})$ for RNA synthesis recovery in media supplemented with $1 \%$ FCS. Cells were then incubated for different time periods $(0.5 \sim 4 \mathrm{~h})$ with serum-free media supplemented with various concentrations of EU $(50 \sim 1000 \mu \mathrm{M})$. Incorporated EU was detected as described in Materials and Methods. Image acquisition and data processing were automated using the automated system. (B) Typical RNA synthesis images captured by the In-Cell-Analyzer. Normal 48BR cells were cultured in 96-well plates and UVC irradiated $\left(5 \mathrm{~J} / \mathrm{m}^{2} ;+\mathrm{UV}\right)$ or mock-treated (-UV). Cells were then incubated for $2 \mathrm{~h}$ for RNA labeling with serum-free media supplemented with $100 \mu \mathrm{M}$ EU. (C) Effect of EU concentration on RNA labeling. 48BR cells were incubated for $2 \mathrm{~h}$ in media supplemented with various concentrations of EU $(50 \sim 1000 \mu \mathrm{M})$. (D) Effect of incubation time on RNA labeling. 48BR cells were incubated for different time periods in media supplemented with $100 \mu \mathrm{M}$ EU. (E) Effects of UV dose and RNA synthesis recovery time-period for the RRS assay. Normal 48BR (closed symbols) and CS-patient-derived CS10LO (open symbols) cells were UVC irradiated at the indicated doses $\left(5 \sim 20 \mathrm{~J} / \mathrm{m}^{2}\right)$, followed by incubation for different time periods $(0 \sim 24 \mathrm{~h})$ in media supplemented with $1 \%$ FCS to allow RNA synthesis recovery. Subsequently, RNA was labeled for $2 \mathrm{~h}$ in a serum-free medium supplemented with $100 \mu \mathrm{M}$ EU.

Figure 4. EU-based semi-automated RRS assay distinguishes between GGR and TCR compromised XP cells. (A) EU-based RNA synthesis recovery assay on normal and NERdeficient fibroblasts were performed at once in a single 96-well plate. (B-H) The indicated human primary fibroblasts were seeded into a 96-well plate in quintuplicate and UVC irradiated (closed bars, $5 \mathrm{~J} / \mathrm{m}^{2}$; open bars, no-UV) as described in Figure 2. The cells were incubated for $4 \mathrm{~h}$ in media supplemented with $1 \%$ FCS to allow RNA synthesis recovery, followed by RNA labeling for $2 \mathrm{~h}$ in a serum-free medium supplemented with $100 \mu \mathrm{M} E U$. Cells were then processed as described in Figure3. Bars or data points, and error bars indicate average fluorescent intensity of discrete nuclei and standard errors, respectively. RRS levels were normalised and expressed as percentages of the average RNA synthesis levels in unirradiated cells (red lines). Student's t-test was performed to evaluate differences in RRS levels between cell lines: 48BR vs. 1BR, not significant $(\mathrm{p}=0.2)$; XP13BR vs. XP21BR, not significant ( $\mathrm{p}=0.8)$; 48BR vs. CS10LO, 48BR vs. XP21BR and XP21BR vs. CS10LO, significant $(\mathrm{p}<0.01)$.

Figure 5. UDS assayed in normal and XP-patient derived lymphoblastoid samples. (A) An experimental scheme of the UDS assay for lymphoblastoid samples. Lymphoblastoid cells 
were cultured for $72 \mathrm{~h}$ in low-serum media to diminish the number of cells in S-phase. Cells were then UVC irradiated $\left(20 \mathrm{~J} / \mathrm{m}^{2}\right)$, followed by $1 \mathrm{~h}$ incubation in serum-free medium supplemented with $10 \mu \mathrm{M}$ EdU. Cells were then fixed and permeabilised, and processed as detailed in Materials and Methods. The azide-coupling reaction was performed in eppendorf tubes. Processed cells were then cytospin-centrifuged, and images captured and analysed by the In-Cell-Analyzer. (B-E) Lymphoblastoid cells derived from normal, and XP-patients were assayed by the system. Histograms of the UDS assay with irradiated (closed bars) and unirradiated (open bars) cells are shown.

Figure 6. A pilot experiment for prospective siRNA-screening performed by the automated system. (A) Experimental scheme of the siRNA transfection and subsequent NER-activity assayed by the automated system. $(\mathbf{B}, \mathbf{C})$ Cells were transfected with indicated siRNAs prior to UV irradiation, and NER-activity was measured as described in (A). (B) UDS activities in cells depleted for XP and NER-unrelated genes. UDS activity was normalised against samples which were transfected with non-targeting control siRNA. (C) RRS activities in cells depleted for XP genes. RNA synthesis recovery levels were normalised against the RNA synthesis levels in unirradiated cells. Error bars indicate standard errors of means of measurements in triplicate wells.

\section{REFFERENCES}

[1] E.C. Friedberg, G.C. Walker, W. Siede, R.D. Wood, R.A. Schultz, T. Ellenberger, DNA Repair and Mutagenesis, 2 ed, ASM Press, 2005.

[2] K.H. Kraemer, N.J. Patronas, R. Schiffmann, B.P. Brooks, D. Tamura, J.J. DiGiovanna, Xeroderma pigmentosum, trichothiodystrophy and Cockayne syndrome: a complex genotype-phenotype relationship, Neuroscience, 145 (2007) 1388-1396.

[3] A.R. Lehmann, DNA repair-deficient diseases, xeroderma pigmentosum, Cockayne syndrome and trichothiodystrophy, Biochimie, 85 (2003) 1101-1111. [4] J.E. Cleaver, Cancer in xeroderma pigmentosum and related disorders of DNA repair, Nat Rev Cancer, 5 (2005) 564-573.

[5] S.C. Shuck, E.A. Short, J.J. Turchi, Eukaryotic nucleotide excision repair: from understanding mechanisms to influencing biology, Cell Res, 18 (2008) 64-72.

[6] D. Bootsma, K.H. Kraemer, J.E. Cleaver, J.H. Hoeijmakers, Nucleotide excision repair syndromes: Xeroderma pigmentosum, Cockayne syndrome and Trichothiodystrophy., in: C.R. Scriver, A.L. Beaudet, W.S. Sly, D. Valle (Eds.) The Metabolic and Molecular Bases of Inherited Disease, 8 ed., McGraw-Hill, New York, 2001, pp. 677-703.

[7] L.C. Gillet, O.D. Scharer, Molecular mechanisms of mammalian global genome nucleotide excision repair, Chem Rev, 106 (2006) 253-276.

[8] P.C. Hanawalt, G. Spivak, Transcription-coupled DNA repair: two decades of progress and surprises, Nat Rev Mol Cell Biol, 9 (2008) 958-970.

[9] M. Stefanini, P. Lagomarsini, S. Giliani, T. Nardo, E. Botta, A. Peserico, W.J. Kleijer, A.R. Lehmann, A. Sarasin, Genetic heterogeneity of the excision repair defect associated with trichothiodystrophy, Carcinogenesis, 14 (1993) 1101-1105. 
[10] L.V. Mayne, A.R. Lehmann, Failure of RNA synthesis to recover after UV irradiation: an early defect in cells from individuals with Cockayne's syndrome and xeroderma pigmentosum, Cancer Res, 42 (1982) 1473-1478.

[11] C. Masutani, R. Kusumoto, A. Yamada, N. Dohmae, M. Yokoi, M. Yuasa, M. Araki, S. Iwai, K. Takio, F. Hanaoka, The XPV (xeroderma pigmentosum variant) gene encodes human DNA polymerase eta, Nature, 399 (1999) 700-704.

[12] A.R. Lehmann, S. Stevens, A rapid procedure for measurement of DNA repair in human fibroblasts and for complementation analysis of xeroderma pigmentosum cells, Mutat Res, 69 (1980) 177-190.

[13] S. Limsirichaikul, A. Niimi, H. Fawcett, A. Lehmann, S. Yamashita, T. Ogi, A rapid non-radioactive technique for measurement of repair synthesis in primary human fibroblasts by incorporation of ethynyl deoxyuridine (EdU), Nucleic Acids Res, 37 (2009) e31.

[14] A. Salic, T.J. Mitchison, A chemical method for fast and sensitive detection of DNA synthesis in vivo, Proc Natl Acad Sci U S A, 105 (2008) 2415-2420.

[15] C.Y. Jao, A. Salic, Exploring RNA transcription and turnover in vivo by using click chemistry, Proc Natl Acad Sci U S A, 105 (2008) 15779-15784.

[16] C.F. Arlett, M.H. Green, A. Priestley, S.A. Harcourt, L.V. Mayne, Comparative human cellular radiosensitivity: I. The effect of SV40 transformation and immortalisation on the gamma-irradiation survival of skin derived fibroblasts from normal individuals and from ataxia-telangiectasia patients and heterozygotes, Int J Radiat Biol, 54 (1988) 911-928.

[17] C.F. Arlett, P.N. Plowman, P.B. Rogers, C.N. Parris, F. Abbaszadeh, M.H. Green, T.J. McMillan, C. Bush, N. Foray, A.R. Lehmann, Clinical and cellular ionizing radiation sensitivity in a patient with xeroderma pigmentosum, Br J Radiol, 79 (2006) 510517.

[18] S. Moriwaki, M. Stefanini, A.R. Lehmann, J.H. Hoeijmakers, J.H. Robbins, I. Rapin, E. Botta, B. Tanganelli, W. Vermeulen, B.C. Broughton, K.H. Kraemer, DNA repair and ultraviolet mutagenesis in cells from a new patient with xeroderma pigmentosum group $\mathrm{G}$ and cockayne syndrome resemble xeroderma pigmentosum cells, J Invest Dermatol, 107 (1996) 647-653.

[19] D.L. Mallery, B. Tanganelli, S. Colella, H. Steingrimsdottir, A.J. van Gool, C. Troelstra, M. Stefanini, A.R. Lehmann, Molecular analysis of mutations in the CSB (ERCC6) gene in patients with Cockayne syndrome, Am J Hum Genet, 62 (1998) 77 85.

[20] H. Tohda, A. Oikawa, T. Katsuki, Y. Hinuma, M. Seiji, A convenient method of establishing permanent lines of xeroderma pigmentosum cells, Cancer Res, 38 (1978) 253-256.

[21] A.R. Lehmann, A.F. Thompson, S.A. Harcourt, M. Stefanini, P.G. Norris, Cockayne's syndrome: correlation of clinical features with cellular sensitivity of RNA synthesis to UV irradiation, J Med Genet, 30 (1993) 679-682.

[22] B.F. Droy, M.R. Miller, T.M. Freeland, D.E. Hinton, Immunohistochemical detection of CCl4-induced, mitosis-related DNA synthesis in livers of trout and rat, Aquatic Toxicology, 13 (1988) 155-166.

[23] F. Vincent, J. Ceraline, S. Goldblum, C. Klein-Soyer, J.P. Bergerat, A new flow cytometric method to follow DNA gap filling during nucleotide excision repair of UVc-induced damage, Cytometry, 45 (2001) 96-101. 
[24] S. Hashimoto, K. Egawa, H. Ihn, S. Tateishi, Non-radioisotope method for diagnosing photosensitive genodermatoses and a new marker for xeroderma pigmentosum variant, J Dermatol, 36 (2009) 138-143. 
A

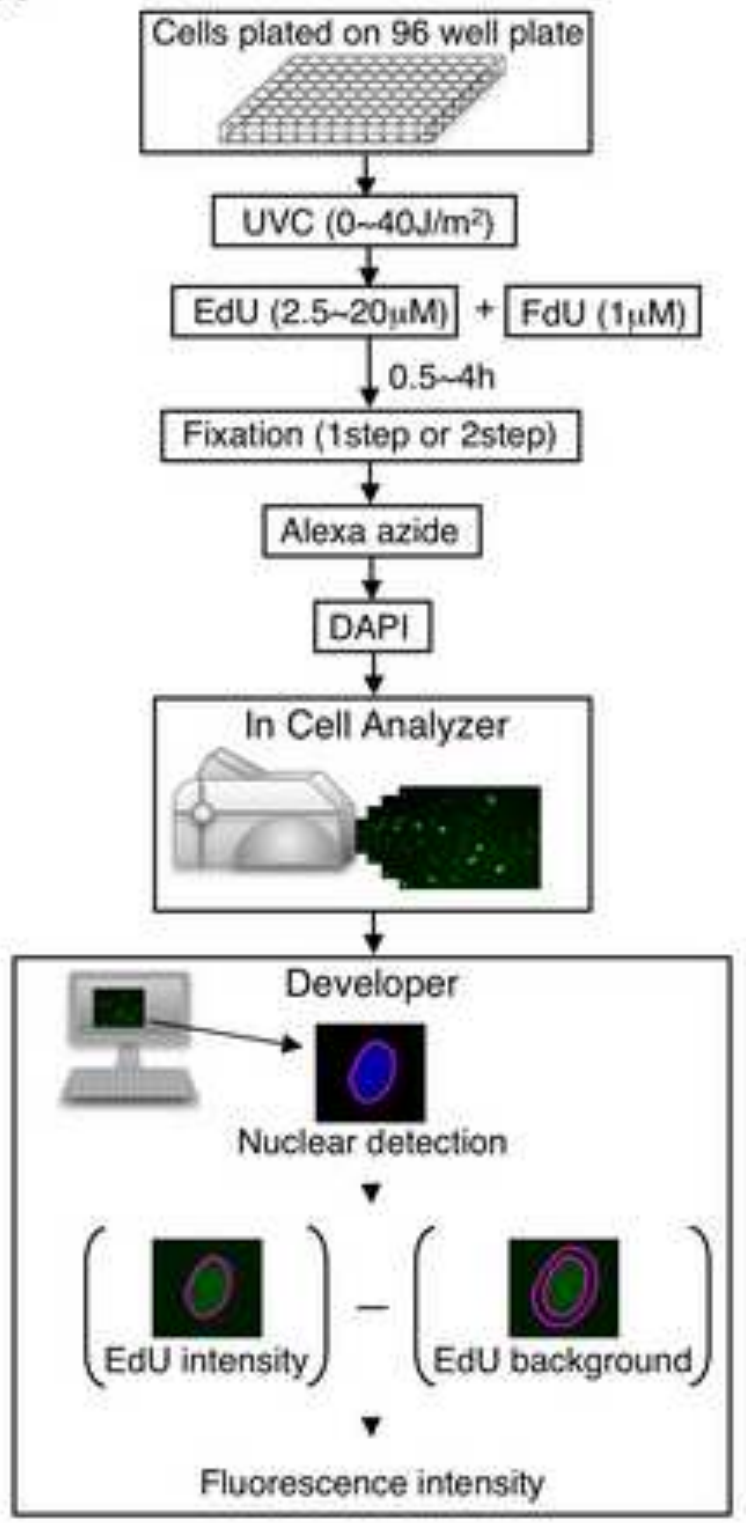

D

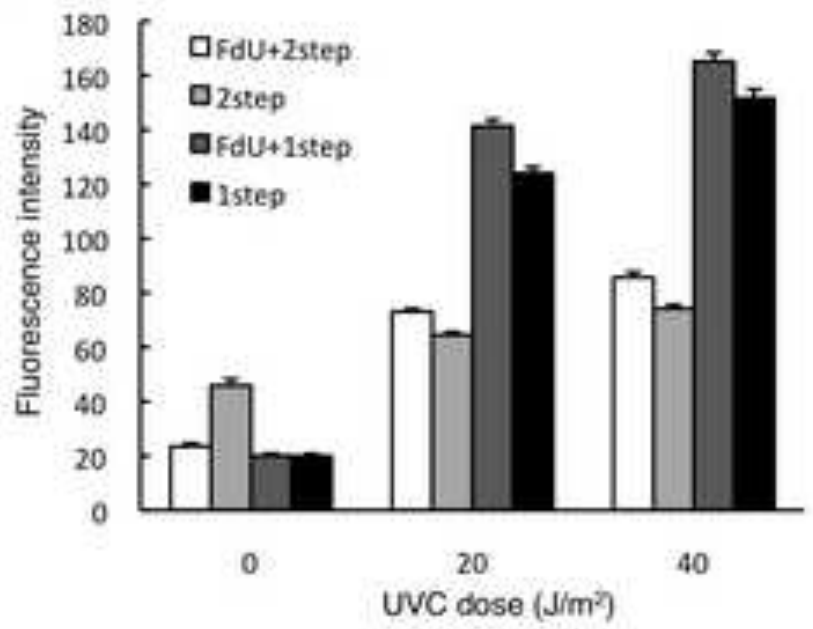

B
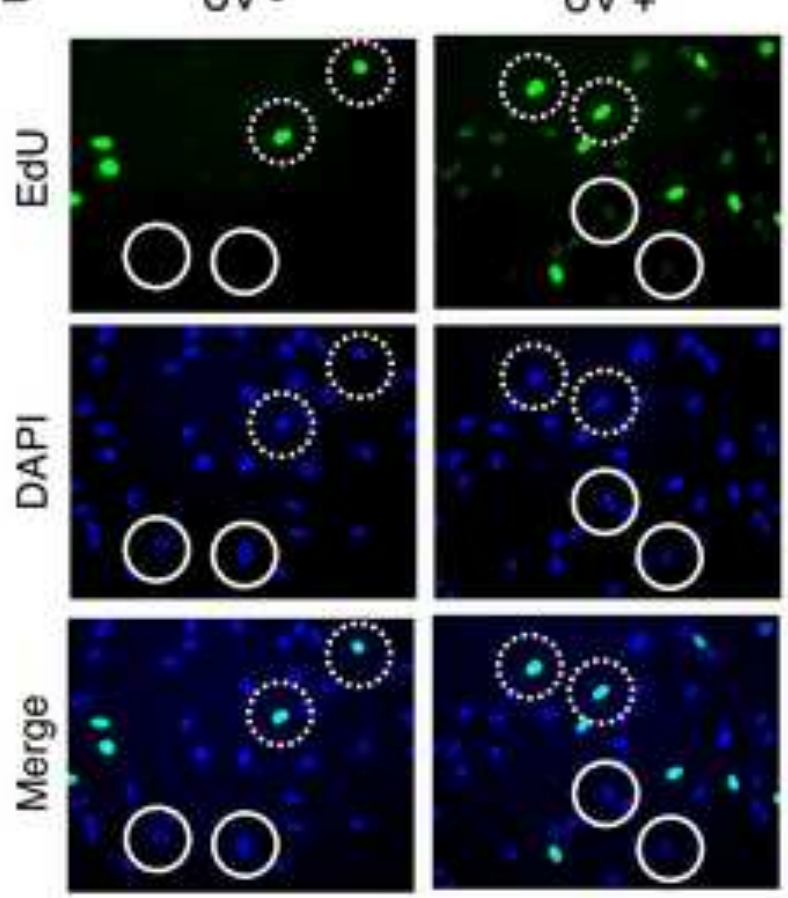

C

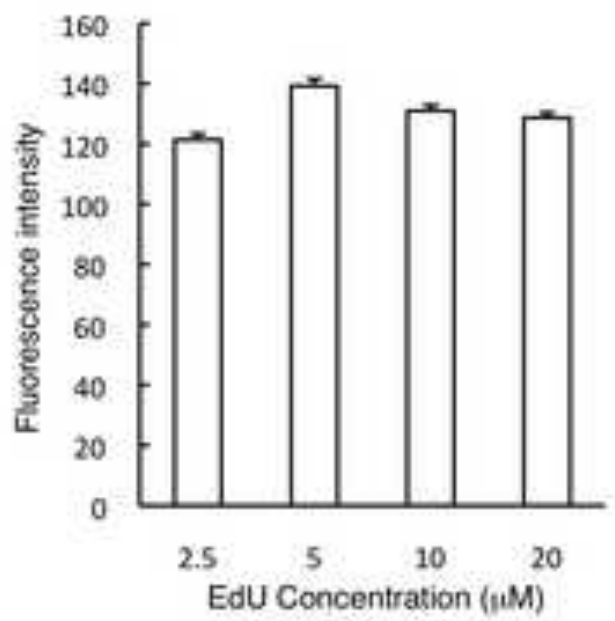

E

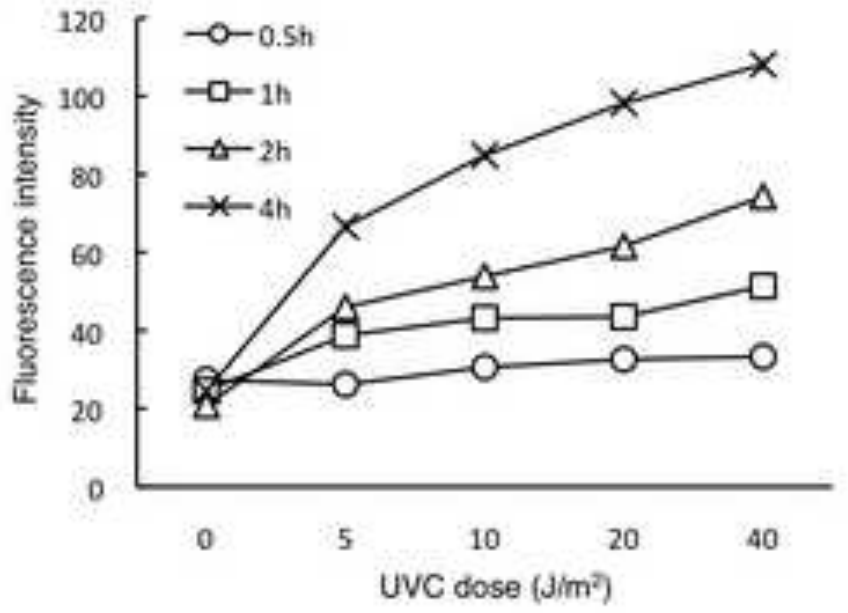


A

$\frac{U V+}{1234567 \frac{U V}{89101112}}$
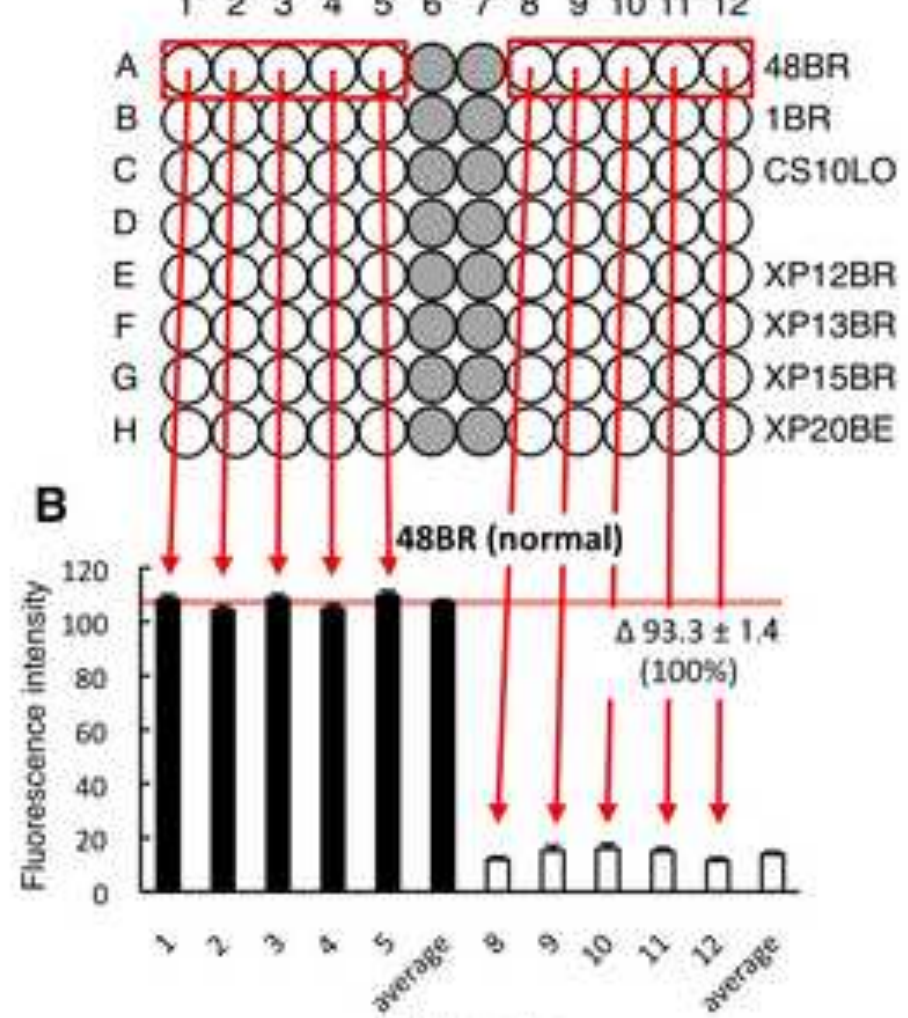

C

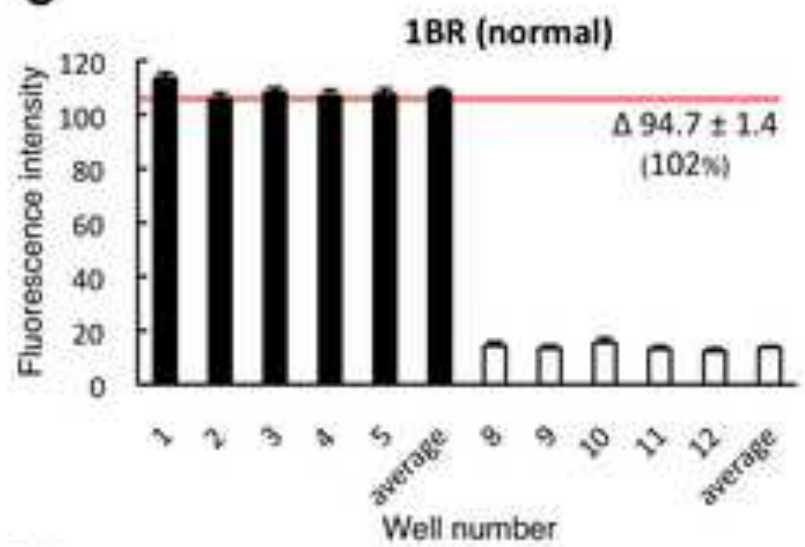

D

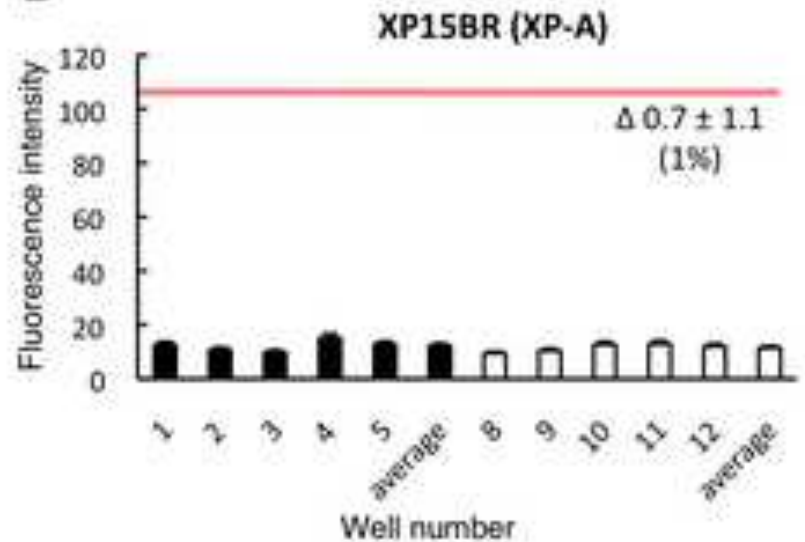

Well number
E

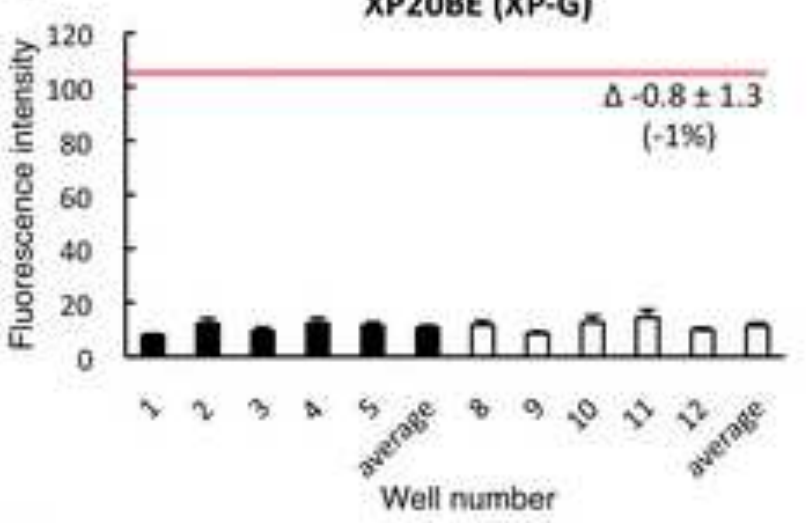

F

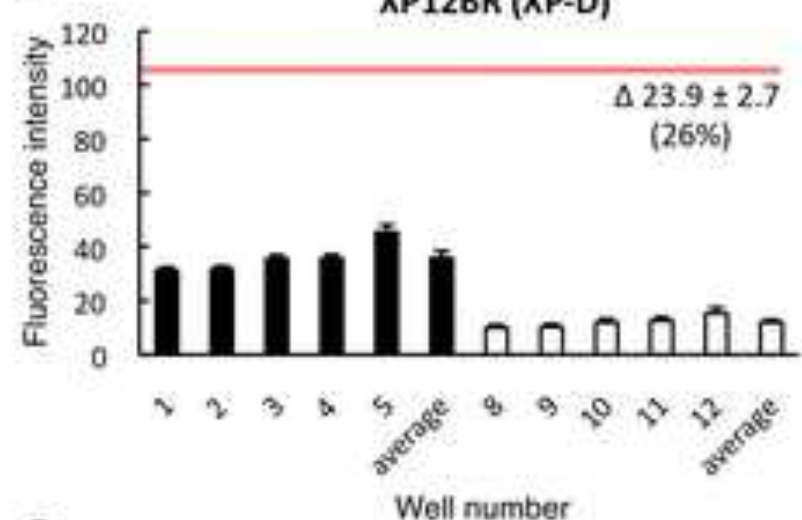

G

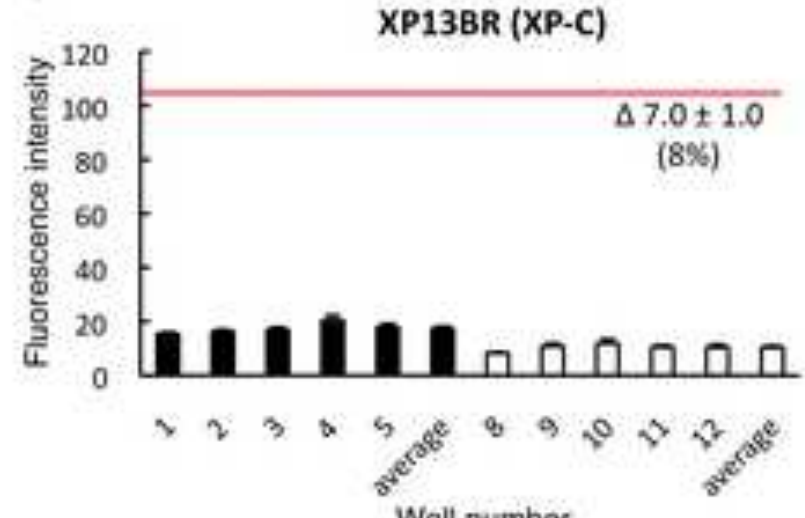

H

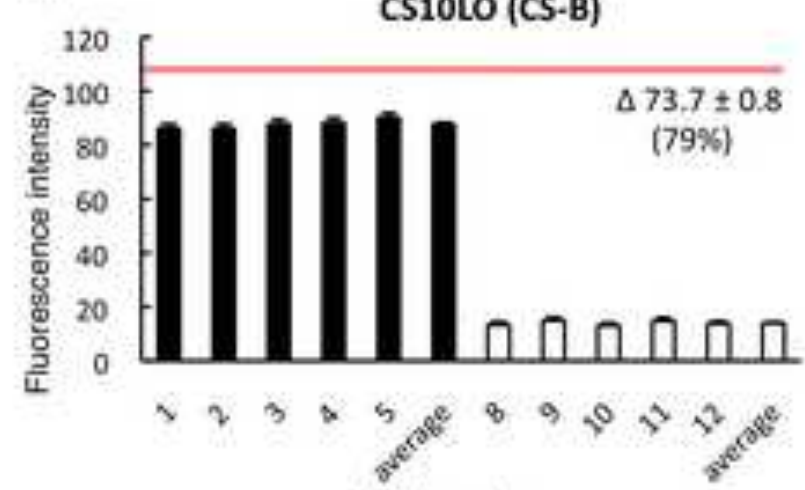

Well number 
A

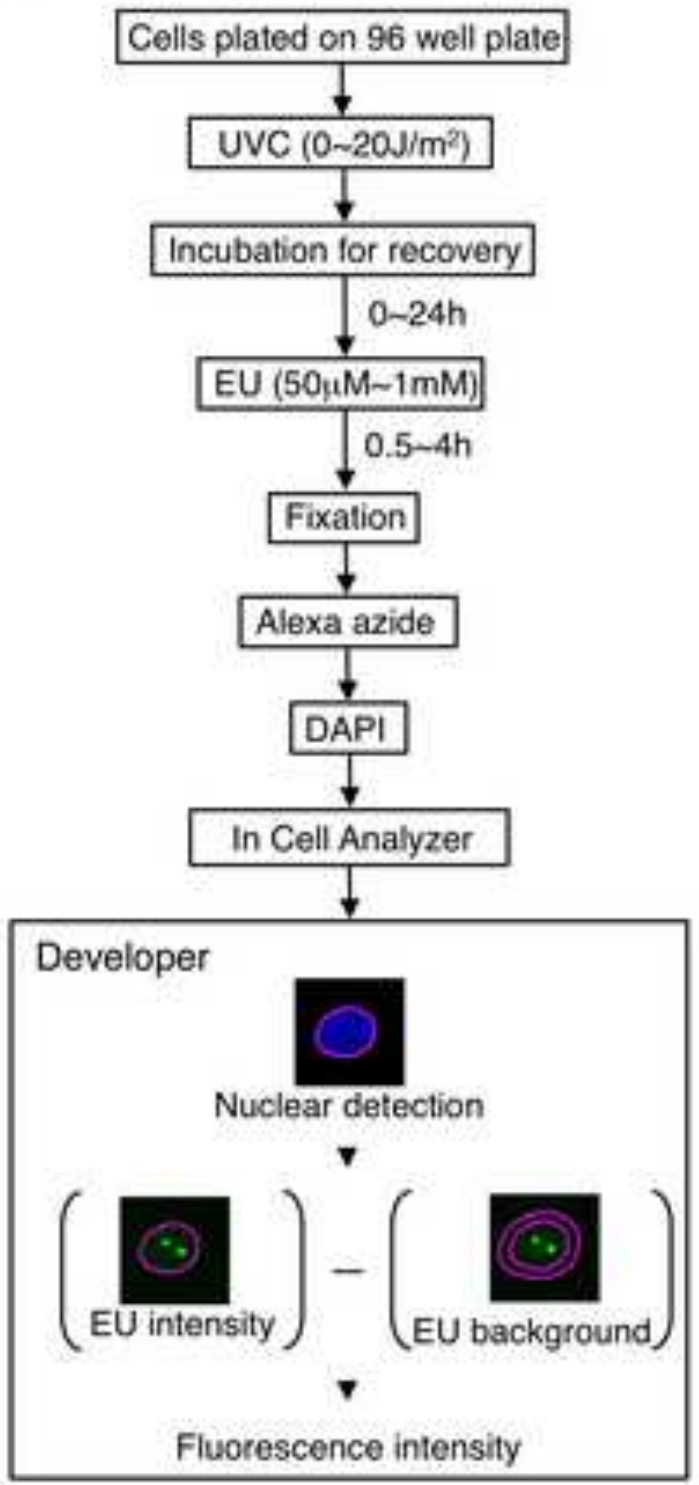

B
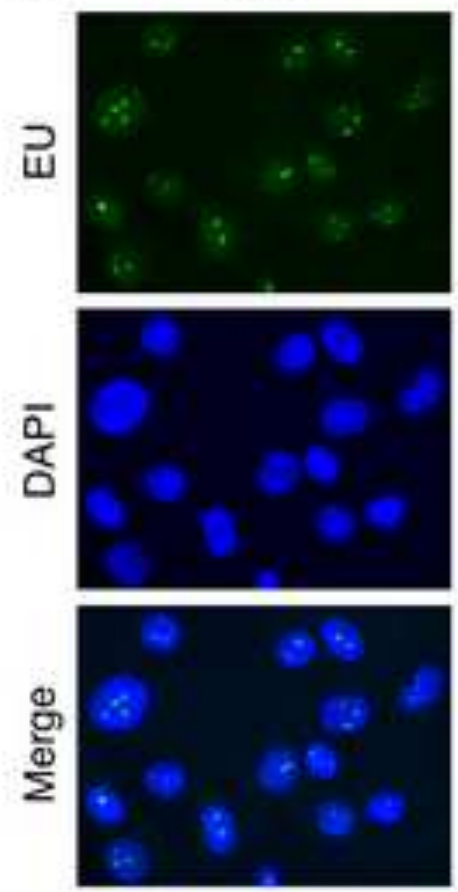

C

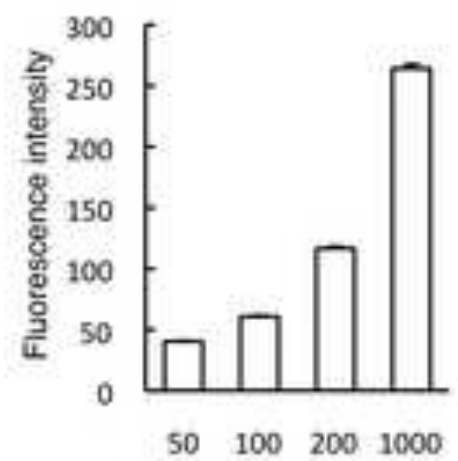

EU concentration ( $\mathrm{MM}$ )
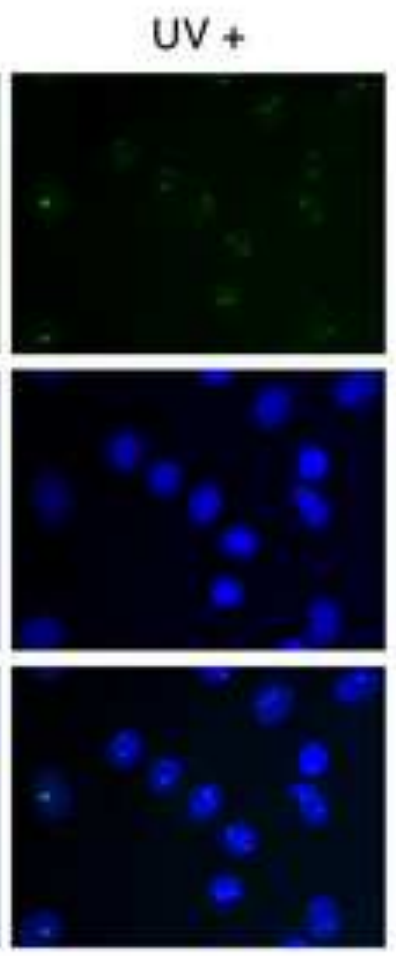

D

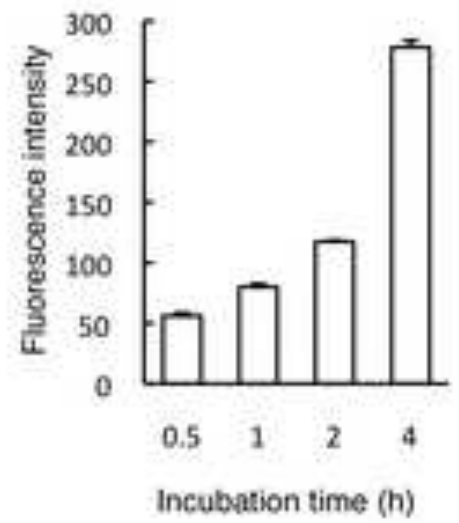

E

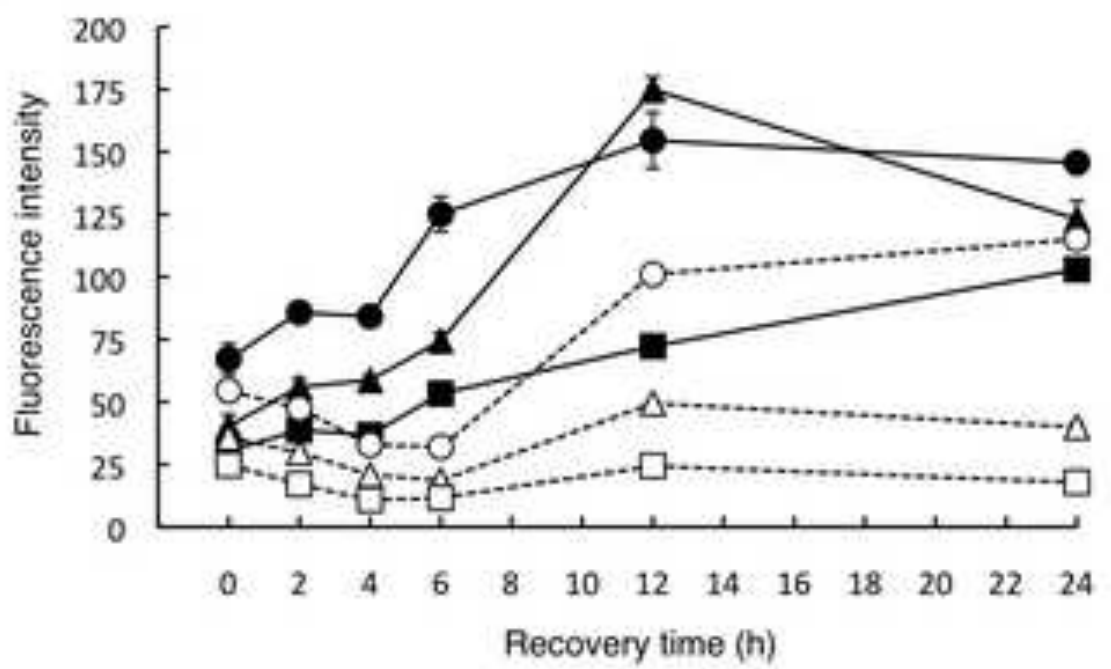

UV dose $\left(1 / \mathrm{m}^{2}\right)$

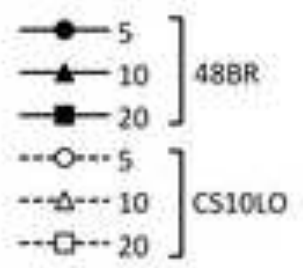


A

$\frac{U V+}{123456789101112}$

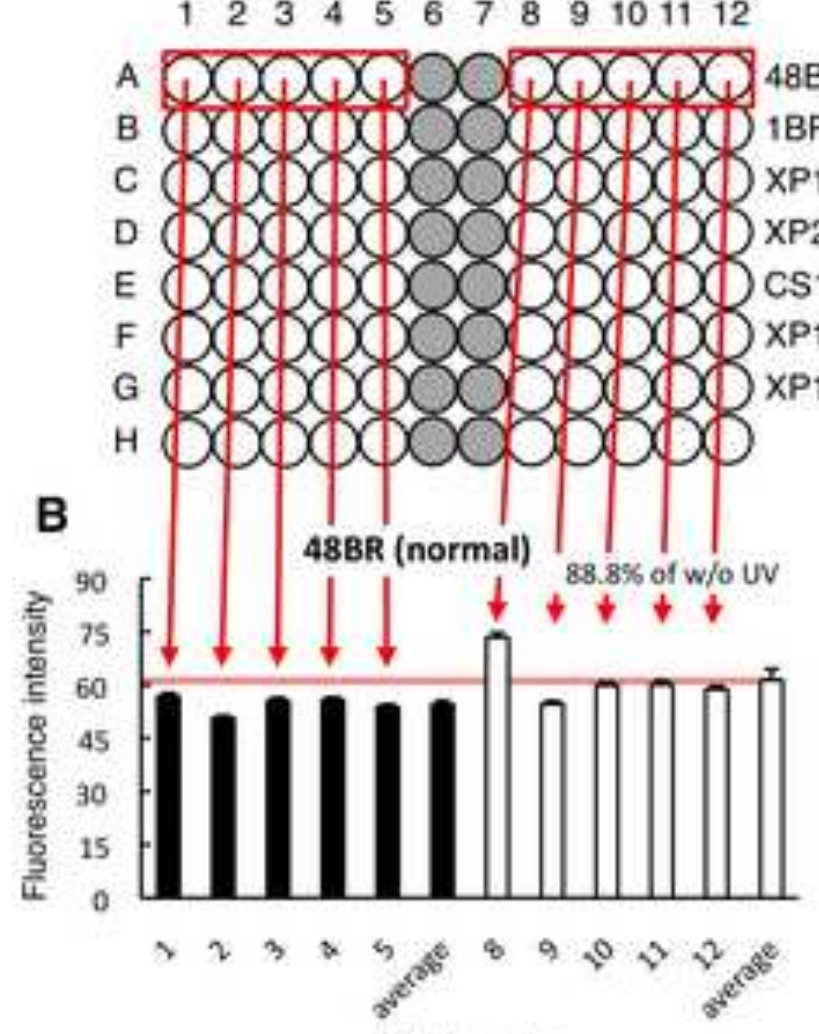

C

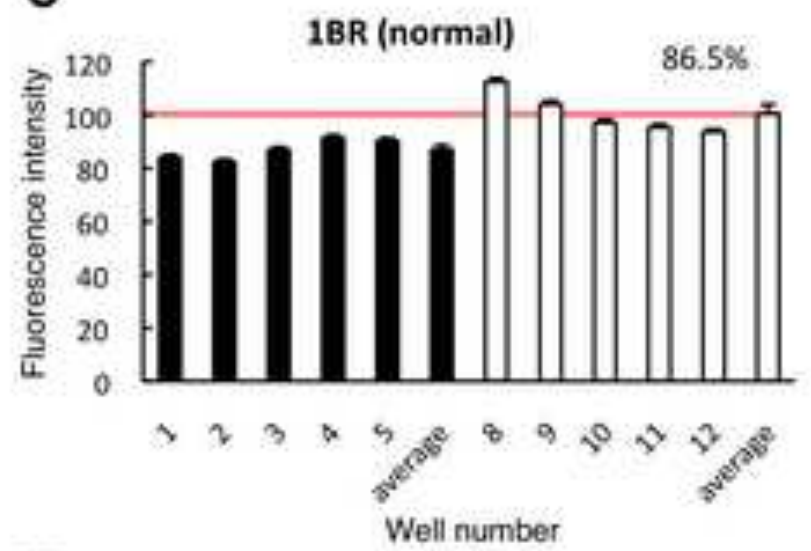

D

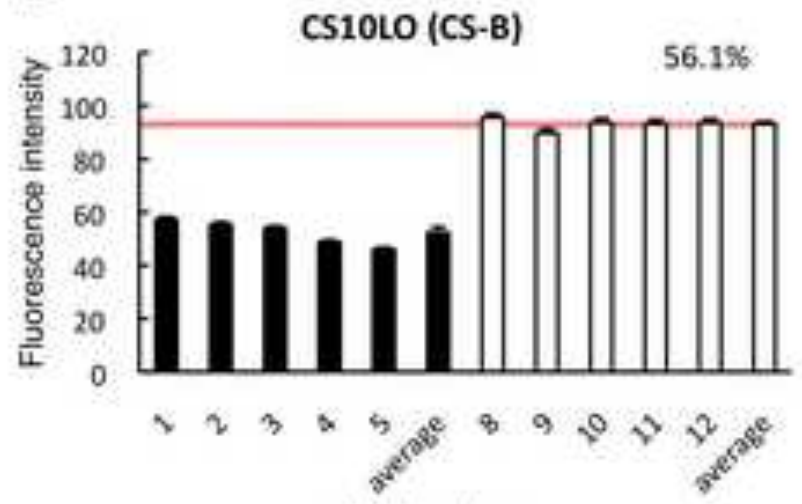

Well number
E

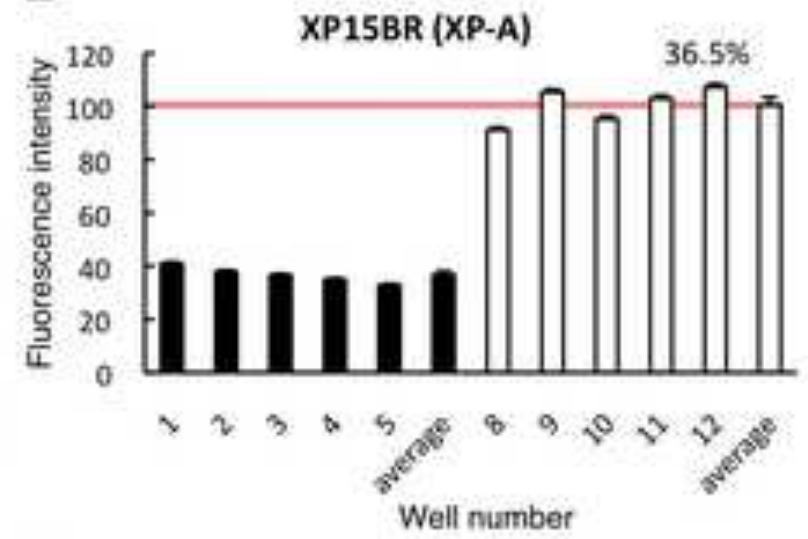

F

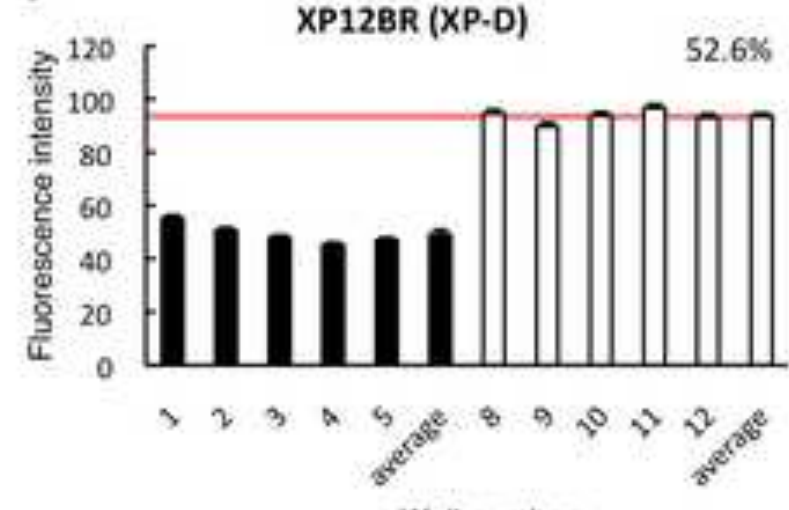

G

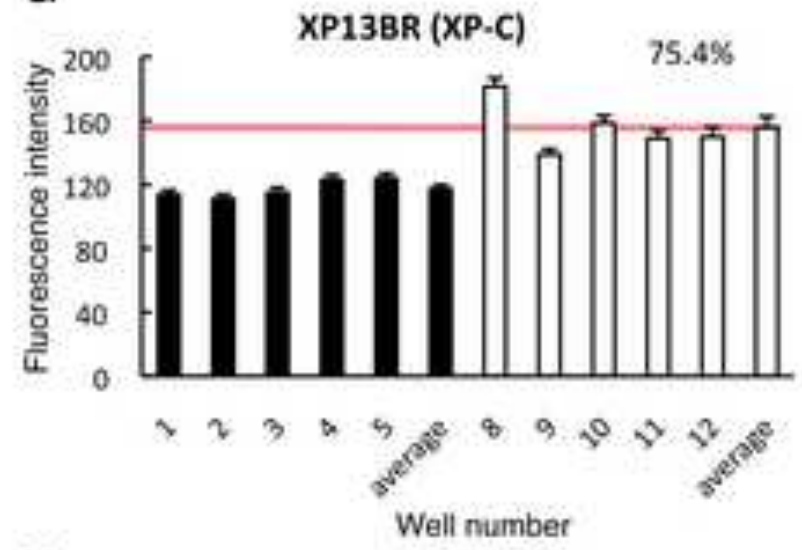

H

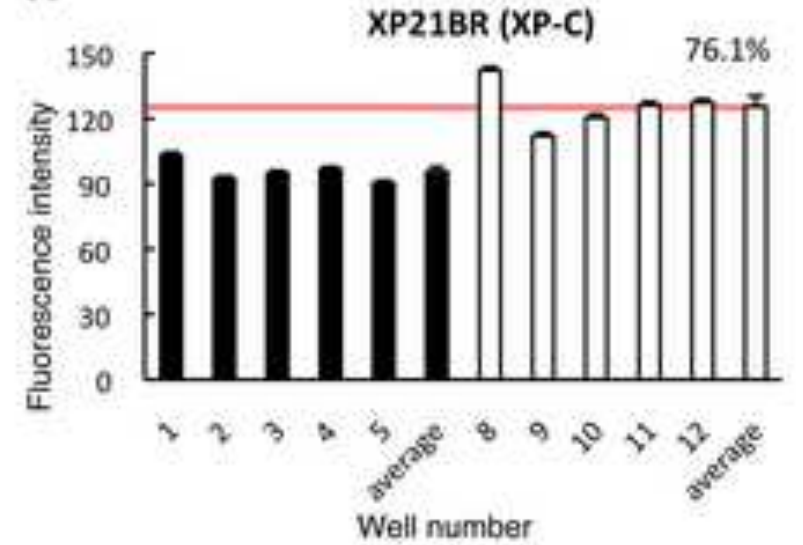

Fig.4 
A

Cells cultured in $1 \%$ FCS Medium

$72 \mathrm{~h}$

UVC $\left(0,20 . / / m^{2}\right)$

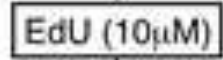

$1 \mathrm{~h}$

Fixation

Alexa azide

$\frac{1}{D A P I}$

$\leftrightarrow$ cytospin

In Cell Analyzer
B

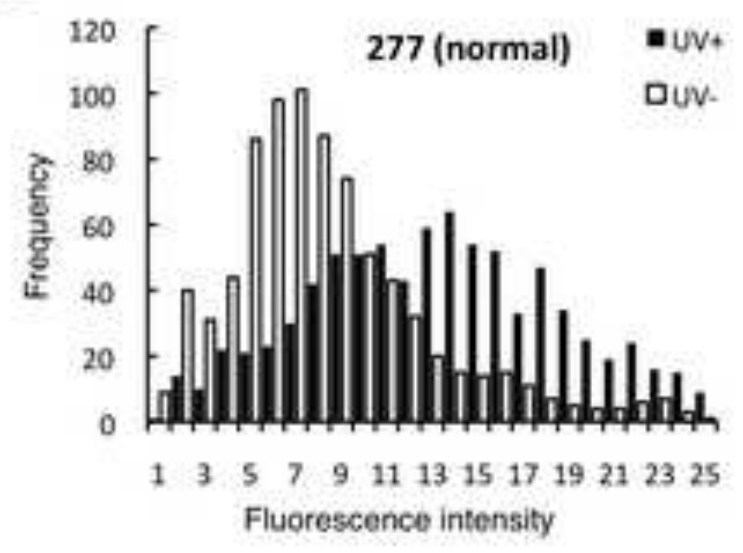

D

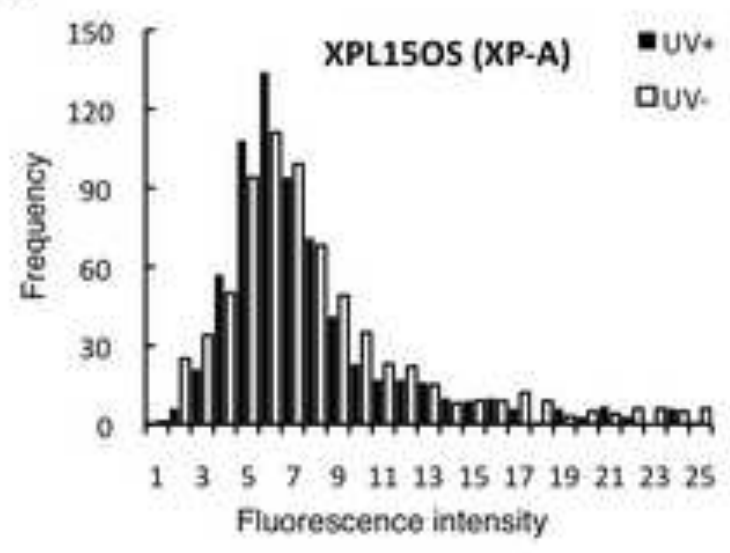

C

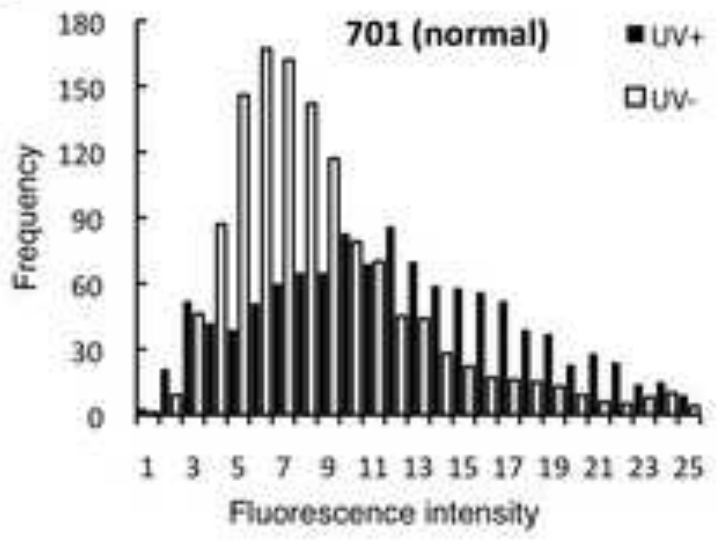

E

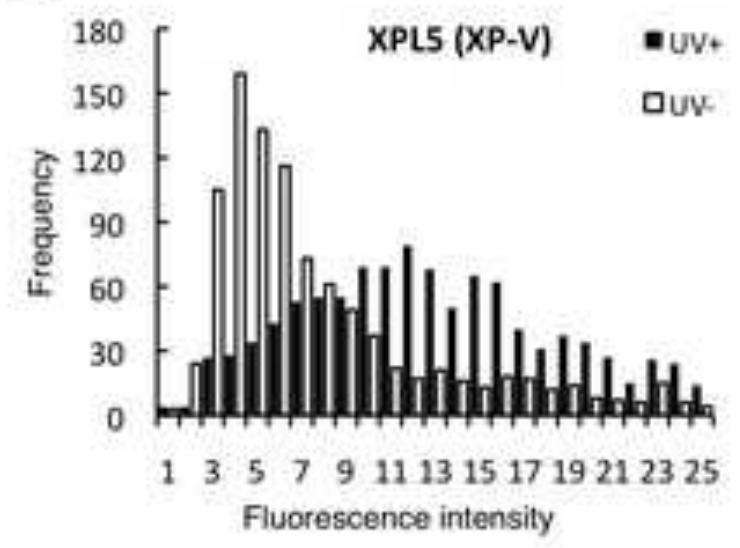




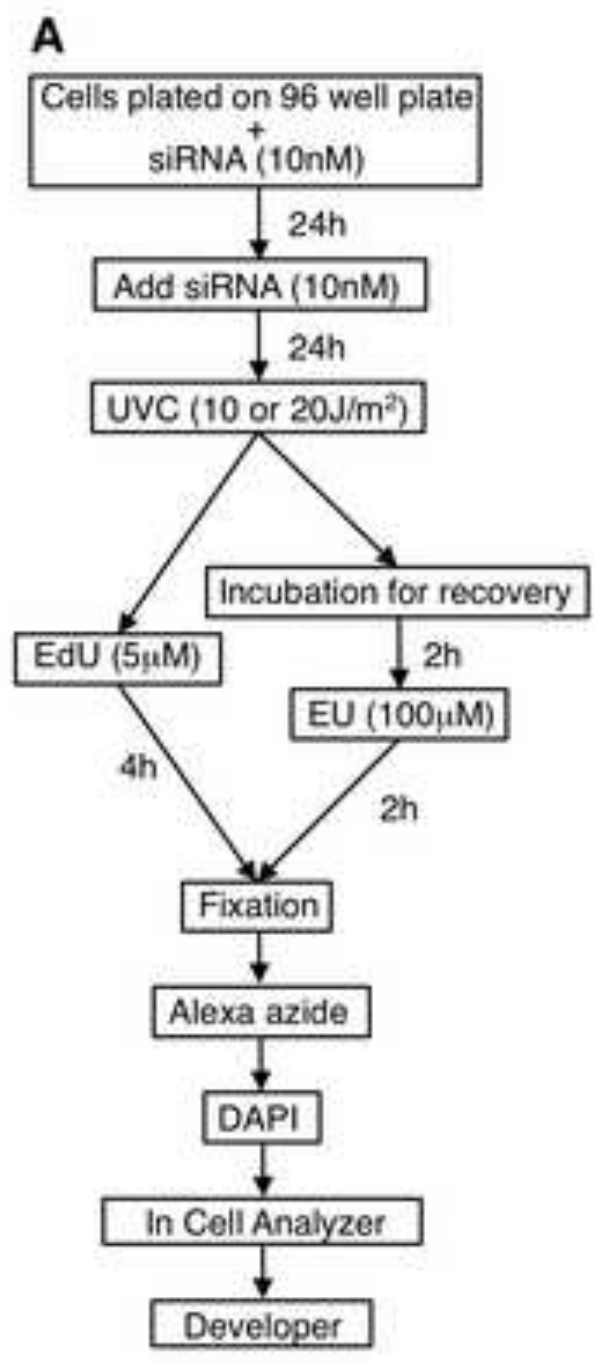

B

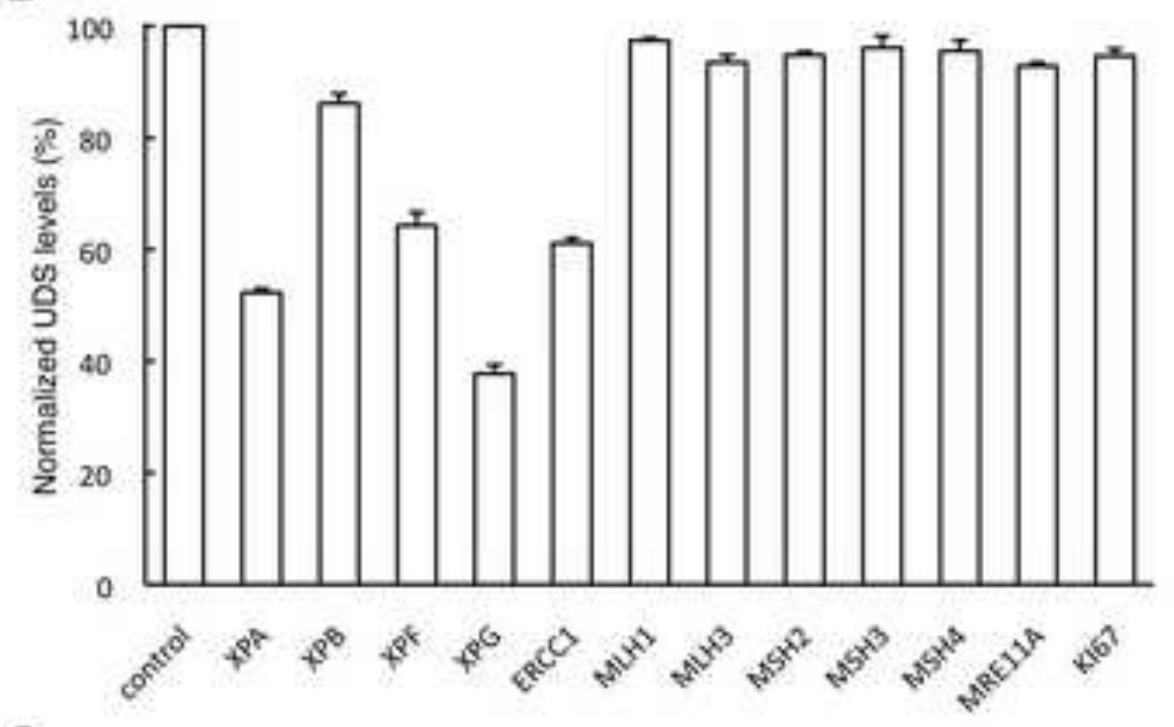

C

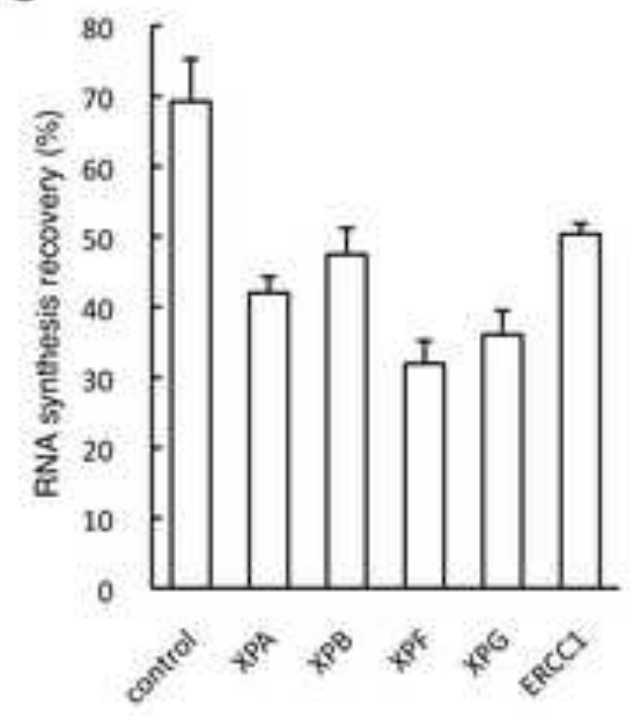

Fig.6 